\title{
Light Pollution and BIM Application
}

\author{
Yingxia YU \\ School of Civil Engineering \\ Henan University of Science and Technology \\ Luo Yang, China \\ e-mail: zhuzhu163zyl@163.com
}

\author{
Yali ZHU \\ School of Civil Engineering \\ Henan University of Science and Technology \\ Luo Yang, China \\ e-mail:252178672@qq.com
}

\begin{abstract}
This paper briefly introduced the BIM technology, the features and hazards of light pollution, combined the BIM technology with the light environment simulation analysis, and further expanded the BIM application, thus it can prevent and control light pollution effectively from the phase of the architecture design. After establishing the modeling used three-dimensional analysis of sunlight to the construction or building cluster, it can be early discovered and solved that building blocked the sun and the sunshine time was insufficient, moreover, it can reduce the occurrence of light pollution effectively by using of the BIM technology.
\end{abstract}

Keywords-light pollution; BIM; light environment; sunshine simulation

\section{INTRODUCTION}

Recently, the pollution of environment increases greatly, people pay more and more attention to the prevention and control of water pollution, air pollution, noise pollution and so on, but give insufficient emphas is to the light pollution. Generalized light pollution refers to some things that may have adverse effects on human visual environment and physical health.

The harmfulness is obvious; it may endanger public health, damage to the stability of ecosystem, increase the incidence of traffic accidents, hamper astronomical observation, and bring trouble to our life and so on. Reducing light pollution must start from the source, reasonable city planning and architectural design could effectively reduce the pollution of the light, to some extent, and necess ary simulation of light environment could reduce it in the link of architectural design. Traditional design was limited to meeting the requirements of the standard light environment, there were some issue though, rules and methods of calculation were too complex, it's difficult to collect data, and the accuracy can't be ensured, as well as bad maneuverability and other issues. Using BIM this tool, not only in line with the green building design specifications, but also easy to operate, on the other hand, it's convenient to design, optimize and remold the design solution for designers.

\section{APPLICATION OF BIM IN THE ANALYSIS OF LIGHT ENVIRONMENT}

\section{A. Light Environment}

Light environment is a component $t$ of the physical environment. The light can be divided into natural light and artificial light according to the light source. For construction, light environment is formed by the light exposure to the space both inside and outside, including outdoor light environment and indoor light environment. Ideal light environment is not only conducive to the visual function of the people to give full play, improve comfort level, but also could abstain or decrease the occurrence of accidents.

The safety, health, convenience, comfort and sustainability of the outdoor light environment should be considered [1], to ensure that the driving safety of vehicles and pedestrian safety. Outdoor lighting should take into account the impact of the residents' living space at night, especially nocturnal sleep; whether the light environment dimension is suitable; whether the lighting equipment caused as brightly lit as in day light and so on. Chinese relevant environmental lighting standards of construction, lighting or formulated by other industries: Code for construction and quality acceptance of city road lighting engineering construction (CJJ89-2001), Lighting design and testing standards for sports venues include provisions (JGJ1532007), Standards about urban night lighting design (JGJ/T163-2008), Definitive standard of lighting and light pollution in ballroom (WH0201-94), Design Standards of urban road lighting (CJJ45-2006), Terminology Standards for building lighting (GTJ/T119-2008), and so on. At present, our country mainly limits light pollution to the locale of lighting through these standards [2].

\section{B. Application Status of BIM}

Dr. Chuck Eastman who majored in architecture and computer science in the Georgia institute of technology created the BIM concept in 1975. That was Building information modeling integrated all the geometry information, functional requirements and component performance, contained all the information in the whole lifecycle of a construction project and integrated into a separate building model, as well as included the process information of the construction schedule, manufacture process maintenance management [3]. That is relatively complete that the definition of BIM defined by the United 
States National BIM standard (NBIMS) at present. This definition is defined as follows: BIM is a digital representation of the physical infrastructure and functional properties; a sharing of knowledge and resource; a process of sharing information about the facility; provides a reliable basis for all decisions of this facility from the conceptual design to the demolition phase of the life-cycle; through the BIM to insert, extract, update and modify information in order to support and reflect the respective responsibilities of the collaborative work at different stages of the project and different stakeholders [4].

Generally speaking, BIM refers to a technology, methods or processes that express the geometric, physical and functional information to support the project life cycle construction, operation, management decisions by using mathematical techniques [5], almost covering the geometry, spatial relations, computer software, geographic information, the building materials, the characteristics and the number of components, animation, etc. At the most basic level, BIM is building+ information+ molding, using the construction components of digitization, informationization, and intelligence to simulate or show the building components used to construction throughout the project cycle in real world.

Effect and value of BIM brought to the construction industry will be more than CAD that commonly used at this stage, it's the inevitable outcome of the development of modern society and information technology, and it will become a growing trend.

At present, BIM concerning three-dimensional sunlight analysis is to show the duration of sunshine under the circumstance that the building at any elevation and the ground based on the consideration of the shelter at this stage; furthermore, analysis the period of sunshine and sheltered of the building. Existing assessment methods is the system management, using two-dimensional graphic expression, irrespective of the details and facade of the sunshine [5].

\section{LIGHT POLLUTION}

Light pollution includes white light pollution, artificial daytime and color light pollution.

(1) White light pollution: the sun light irradiate the glass curtain wall, polished marble and a variety of paint of the buildings, reflecting the dazzling light and affecting people's outgoing.

(2) Artificial daytime: in the night, LED advertising lamp box, neon lights, and others are very dazzling, some strong beam might straight up into the sky, making night as in the daytime.

(3) Color light pollution: The rotating lamp, the fluorescent lamp, the flash lamp and the color light source which are installed in the bar, the dancing hall and other places are composed of the color light pollution.

With glass curtain wall introduced into our country in the 1980s, a large area used of glass curtain wall buildings can be seen everywhere, but the light pollution has not been effectively control. The light pollution caused by glass curtain wall mainly is white light pollution, refers to: the external wall of the building used a large area of heat reflective coated glass curtain wall, as light from the sun hits the surface of the glass, generate the strong reflected light, interfere with people's normal life and work, some reflected light convergence is easy to cause the occurrence of fire as well. With cars and people moving fluidly in a tight pack, on both sides of the glass curtain wall building, when pedestrians and drivers see the light with all that reflection and refraction, in the radiation of the sun, street lights, neon lights and traffic lights, it could cause them sudden blindness and feel dizzy, and maybe increase the outward, fatalness of dwellers, threaten people's life and safety.

And secondly, light pollution will also affect the quality of residents' life that live in this environment, especially, the harsh light affects indoor living environment and destroy the original atmosphere or temperature. In addition, the unreasonable setting of street lamps, neon lights, and LED advertising display in a way affects our life and outgoing.

The people who live in light pollution environment at a long term probably affected by shortages will be also at significant risk of disease outbreaks: light-headedness, agrypnia, neurasthenia, inducing tachycardia, heart and cerebral vessels disease, people with cardiovascular disease will cause sudden death; intense light pollution also induces skin cancer.

Light pollution not only affects people's daily life in a certain extent, but also may causes a part of the animals' and plants' the normal reproduction, migration, pollination, clock of the biological activity, makes the ecological system with in the various species have become vulnerable, and ultimately will affect human beings.

Light pollution can be produced in a certain environment: (1) using glass material with large area and high index of refraction; (2) setting the LED screen with high brightness and bright colors; (3) formed by refracting and reflecting solar rays and lamplight in a particular direction, time; since the incident angle of the solar light is gradually changing with time and seasons, there is a specific time limit for the light pollution caused by sunlight.

\section{PREVENTING AND CONTROLLING LIGHT POLLUTION}

\section{A. In Harmony with the Surrounding Environment of the Street}

Avoid the use of glass curtain walls on both sides of the road; make them stagger and parallel to each other. In large, open and prosperous commercial section, the glass curtain wall can be used to enhance the beauty of the building, but also to consider the distance between the buildings, control its numbers. Indoor lighting environment has reached the requirement in the construction of the office, business and library, considering it has adopted a large area of floor to ceiling windows and glass windows, so it's not necessary to use the glass curtain walls.

\section{B. Strengthen Urban Planning and Management; Make the Layout of Urban Construction Group Reasonable}

The urban planning management department should control the use of the glass curtain wall, identify the need to use the glass curtain walls on main thoroughfare and 
frontage, considering the city plan, actual requirements, functional features, climatic conditions and so on, in order to minimize the use of glass curtain walls, to avoid the use of them is too concentrated. Attention to reduce the use of high power light, take advantage of plants to block the reflection of light radiation, improve the lighting environment, reduce light pollution damage to the human body and the environment, but also could add to the greenization of our cities and improve the environment. The urban construction department should do a good job in the examination, surveillance and acceptance of light pollution.

\section{Texture of Material}

The existing glass can be treated by a special process to reduce the directional reflection light, without increasing the indoor thermal effect at the same time. Improving the structure of the glass curtain walls, on the one hand, not only could improve the thermal comfort of the building interior, but also save energy and protect environment; on the other hand, could prevent the generation of external light pollution. We can use the different materials to change the reflection strength of light, so as to reduce light pollution.

\section{APPLICATION OF BIM - THE PROPOSED MODEL}

Professional sunshine analys is software is more thorough and professional than existing software of BIM, although the existing BIM software in simulations of light environment just still stay at sun exposure and shadow phase, these software have no features that BIM software has, including informationize, digitization and so on. However, we can further expand potential applications of BIM by specializing in the modules of sunlight analysis in the future. By using BIM three-dimensional visualization and the function of data information, we can input these information from all sides into the BIM software models, these information include sunlight hours, place, materials' osmotic coefficient, reflection coefficient, absorption coefficient and thickness of light, to further expand the development of the module. In the planning and design stage, to a large extent, control the production of light pollution by changing the angle between the reflected light and the person's line of sight, rational planning and design, glass curtain walls' materials, reas onable design of glass curtain walls' building orientation, height, textures and so on.

\section{A. Sunlight Simulation}

With the development of our city, the numbers of high rise building are increasing, besides, land is considered as limited resource. Urban residents also have a certain demand for indoor lighting, and the phenomenon of mutual occlusion between adjacent buildings is increasing. It's necessary to carry out the analysis and simulation of sunlight in the architectural design stage in order to avoid the occurrence of sunlight blocked by other buildings or insufficient sunshine time, etc, to ensure the residents' health living environment.

According to code for planning and design on urban residential areas (the 2002 edition), residential sunshine standards should be consistent with the provisions of it. The specific circumstances shall also conform to the following provisions: (1) sunlight hours of the old people's residential building should not be less than the standard of two hours on a winter solstice; (2) should not reduce the original sunshine standard of neighboring building when the added facilities is based on the original design building; (3) the residential sunshine standard can be reduced when newly-built house is based on the reconstruction project of old area, but they should not be below the standard of one hour on a winter solstice.

According to the relevant provisions of sunshine and shelter of the building, we can carry out the 3D parametric molding to the planning construction and existing buildings, based on the data and information of the geographical position, elevation and so on, and then analysis and simulate the sunshine of the proposed buildings through the related software of BIM: to begin with, simu late actual situation that light hits the building, we can get the information of sunshine duration and dynamic change of shadow through the position of the sun relative to the building and the mutual moving rules between the sun and the earth; second, analyze and identify the sheltered object affected by sunlight condition, through sunshine emulation, then clear and definite relationship between the sheltered buildings for a particular period of time; in the end, analyze and find out the positive role and negative influence of factors to sun exposure, these factors include location, layout, height and size between buildings. After that, make appropriate changes according to the relevant requirements, such as the design of the window location, size, location, etc, thus improve the living comfort of residents, design to meet the demand of building indoor light environment and light. The output mode include 3D analogy dynamic cartoon, a mock up drawing, data analytical report and so on.

As shown in Figure 1, the author uses Revit software to draw the architectural model, and use the existing software to simulate the solar shadow; we can see that sun exposure time is a period of time from 07:33 to $16: 50$ at the Solstice of 2016, and also can analyze every moment of sunshine and shadow shielding case that day.

BIM can be combined with the characteristics of professional analysis software, and the above content could be included, there will be more accurate in data. There are various errors in the analysis of sunlight [6]: the error of the year, position, and time and so on, sunshine simulation cannot reach one hundred percent precision, but it has a certain practical effect to expanding BIM technology, simulation of the situation, the analysis of lighting environment, light shielding and other is sues. 


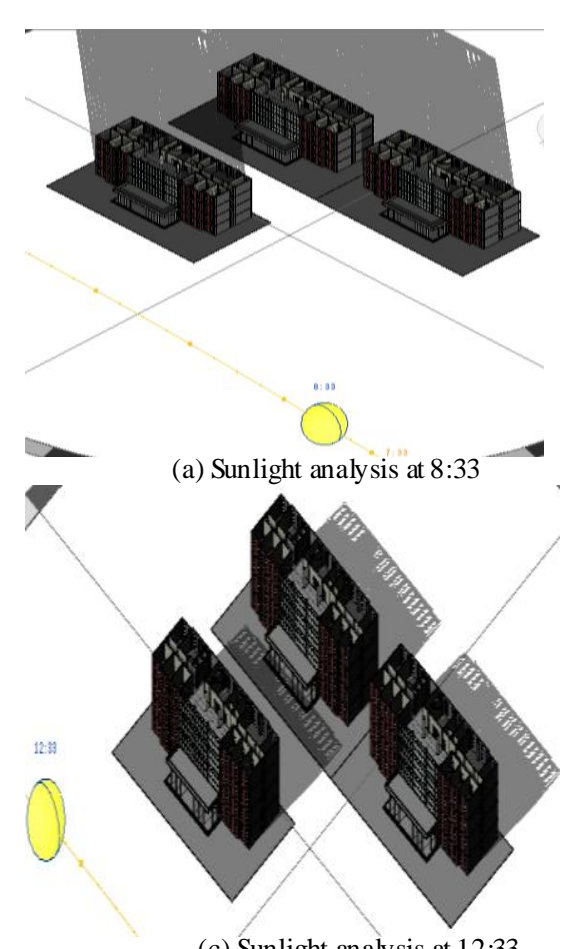

(c) Sunlight analysis at 12:33

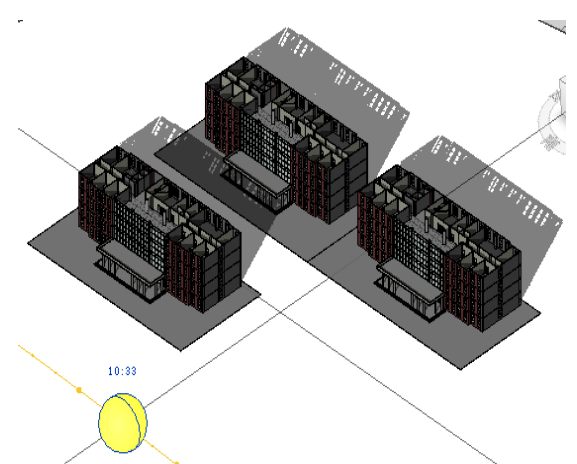

(b) Sunlight analysis at 10:33

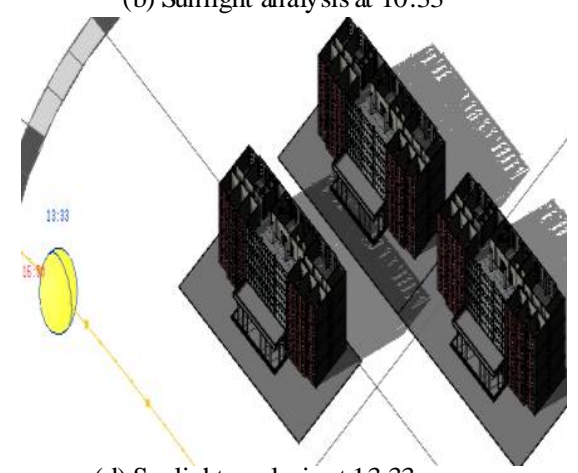

(d) Sunlight analysis at 13:33

Figure 1. Schematic diagram of sunlight analysis (a) (b) (c) (d)

\section{B. LightSimulation of Glass Curtain Wall}

The light pollution of the glass curtain wall has close relationship with the material reflectivity, installation location, climate condition and geographical position of the curtain wall. Reflectivity for glass curtain wall is not the same naturally, because of different materials of surface plating; the geographical position of the curtain wall is different, according to the angle of the sun light and different installation positions, the degree of light pollution is not the same; weather conditions are different including cloudy or rainy days, will make the intensity of sun light exposure to the curtain wall changes; because the orbits of the sun are different in different seasons, the sunlight is right along the Tropic Cancer on the summer solstice day, the sunlight is right along the Tropic of Capricorn on the winter solstice day, all this caused in most area of our country the solar radiation is strong in summer, and the winter is relatively weak; in addition, at the same time but different locations, the solar altitude angle is different, it will cause the reflection light angle of glass curtain wall is different, and then affect the intensity of glare [7].

The degree of light pollution is related to the direction, the position and the height of the glass curtain wall [8]. People's angle of view in the range of 2 meters high and 150degree angle is greatly affected. (First to forth storey buildings should be avoided using glass curtain wall.) The intensity of light reflection is inversely proportional to the square of the distance from the reflection to our eyes. These data could be integrated into BIM software, light propagation and light pollution could have been presented by using 3D visualization and dynamic simulation, then the combination of simulation data and actual unifies has certain optimized significance to the planning and design optimization.

The light environment of the build ing could be simulated and analyzed according to the position of the sun and the earth, the geographical position of the glass curtain wall of a building and the different changes of the solar light intensity in the four seasons. At this stage, the light environment of the BIM is used to simulating the propagation path of the light and the change of the shadow area. The application of BIM in the light environment simulation module is not very deep and awaiting improvement.

\section{CONCLUSION}

This paper is based on the analysis of sunlight in BIM application as a starting point, analyzes the generation, harm and prevention of light pollution. From the source that the building design phase, take effective measures to further control the light pollution. Architectural design stage adds light environment simulation, sunshine analysis module, it can control light pollution to a great extent, it's also more convenient to provide an effective way to solve this problem that city planning, housing purchasing, the transformation of the old city and sunshade. With the continuous improvement of BIM technology, it is bound to bring significant changes in urban planning and management.

\section{REFERENCES}

[1] Ma Jian, Yao Xin, Liu Gang, Su Xiaoming. Study on the Assessment Indicators for Exterior Luminous Environment of Residential Area in the City [J]. China Illuminat ing Engineering Journal, 2010, 01: 1-6. 
[2] Xie Li, Fang Qiaoli, Wu Yanyu, Peng Xiaochun, Yang Renbin, Liu Jie. Research on the Light Environment Management System in China [J]. Environmental Protection Science, 2013, 04: 93-96.

[3] H Edward Goldberg. The Building Information Mode, CADalyst Eugene. Nov2004. Vol. 21, 56-58.

[4] He Qinghua, Qian Lili, Duan Yunfeng, Li Yongkui. Current Situation and Barriers of BIM Implementation [J]. Journal of Engineering Management, 2012(1): 12-16.

[5] He Guanpei, Li Gang. What is the thing called BIM [M]. Beijing: China Building Industry Press, 2011:43-125.
[6] Zhang Jianyuan, Li Zhigang. Discussion on the Related Problems of Sunlight Analysis Occlusion Adjustment [J]. Urban Geotechnical Investigation \& Surveying, 2012, 03: 110-113.

[7] Li Minhang, Qu Xinghua, Geng Xin, Liu Yanhua, Zhang Shoubin. Explore the Classification and Control Values of Light Pollution Monitoring [J]. Environmental Monitoring in China, 2013, 02: 51-54.

[8] Zhao Yunyun. Light Pollution of Glass Curtain Wall and its Control Measures [J]. Doors \& Windows, 2008, 03: 9-13. 